\title{
5 \\ High Resolution Rainfall Information in Urban Run-off Simulation
}

\author{
Niels E. Jensen, Lisbeth Pedersen and Søren Overgaard
}

Local variability in rainfall suggests that precipitation measured by weather radars is necessary for accurate simulation of run-off from urban areas. Short-term spatial variability in accumulated rainfall measured by conventional rain gauges has shown that rainfall information must be established in a 100 by $100 \mathrm{~m}$ grid or smaller. Small radars are an economical solution to this demand.

As a part of a Local Area Weather Radar (LAWR) calibration exercise $15 \mathrm{~km}$ south of Aarhus, Denmark, nine high-resolution rain gauges were used to measure rainfall within a single radar pixel $(500$ by $500 \mathrm{~m})$. The measured values indicate up to a $100 \%$ variation between neighbouring rain gauges within the pixel over a four day period. The rain gauge data and rainfall estimates from the LAWR radar were feed into a run-off model of the pixel to evaluate the impact of point vs. area estimates of rainfall.

\subsection{Introduction}

Traditionally rainfall is measured using rain gauges. These gauges measure the actual amount of rain that falls over an area as small as a few $\mathrm{cm}^{2}$ very accurately. Rainfall estimation derived from Weather Radar is an alternative.

Jensen, N.E., L. Pedersen and S. Overgaard. 2006. "High Resolution Rainfall Information in Urban Run-off Simulation." Journal of Water Management Modeling R225-05. doi: 10.14796/JWMM.R225-05.

(C) CHI 2006 www.chijournal.org ISSN: 2292-6062 (Formerly in Intelligent Modeling of Urban Water Systems. ISBN: 0-9736716-2-9) 
The radar does not measure rain directly, but measures the reflection of electromagnetic waves from the falling droplets over a volume. In order to arrive at the corresponding rainfall, the relation between the reflections and the corresponding rain rate must be established.

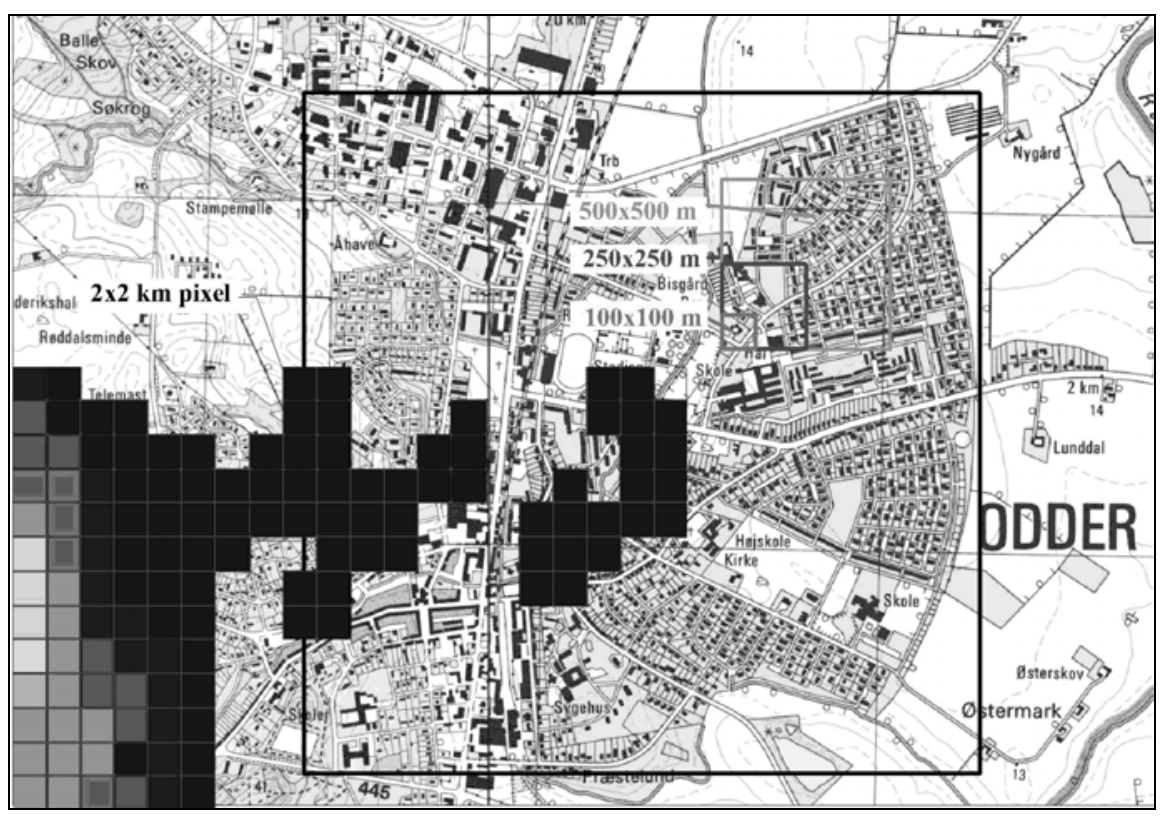

Figure 5.1 A scale indication: $100 \times 100 \mathrm{~m}$ pixel superimposed on the city of Odder, close to the experimental site.

\subsection{Experimental Site and Instruments}

The nine high-resolution optical rain gauges have been placed in one of the Søsterhøj LAWR Radars grid cells as shown in Figure 5.2. The radar grid is marked with dotted lines. A radar grid cell size of 500 by 500 meters is chosen as the corresponding LAWR precipitation measurements. The nine rain gauges are placed so that each represents one ninth of the grid cell area $\left(27,556 \mathrm{~m}^{2}\right)$. The position of each rain gauge was determined and located by 
handheld GPS. The orientation of the rain gauges and their coordinates are shown in Figure 5.2.


Figure 5.2 Location of the nine rain gauges marked with GX. The 500 by 500 meter radar grid is marked with dotted lines. North is upwards. The coordinates for the nine rain gauges are listed to the right.

\subsection{Available Precipitation Data}

The rain gauges were operative in the period from the 21st of September to the 25 th of November 2003. The 65 days of sampling resulted in one time series for each gauge. The nine time series are independent, hereby meaning that the nine gauges have sampled individually and have not been connected in any way. 
The complete time series has been divided into individual events for use in the further data processing. The separation criterion is a minimum of $10 \mathrm{~h}$ between two logs in any gauge, which corresponds to $10 \mathrm{~h}$ without rain. Separation of the series into individual events yields 23 individual events. The data used in this chapter is for event 17.

Table 5.1 Time and precipitation facts for event 17.

\begin{tabular}{lccc}
\hline & Rain gauges & LAWR-500 & LAWR-250 \\
\hline First log & $10-31-03$ 09:38:36 & $10-31-03$ 19:05:00 & 10-31-03 19:05:00 \\
Last log & $11-04-0305: 25: 00$ & $11-03-03$ 17:50:00 & $11-03-03$ 17:50:00 \\
Total duration [hours] & $91: 46: 24$ & $46: 25$ & $46: 25$ \\
Minimum precipitation [mm] & 25.53 & - & 27.14 \\
Maximum precipitation [mm] & 48.94 & - & 28.48 \\
Mean precipitation [mm] & 33.78 & 28.83 & 27.72 \\
\hline
\end{tabular}

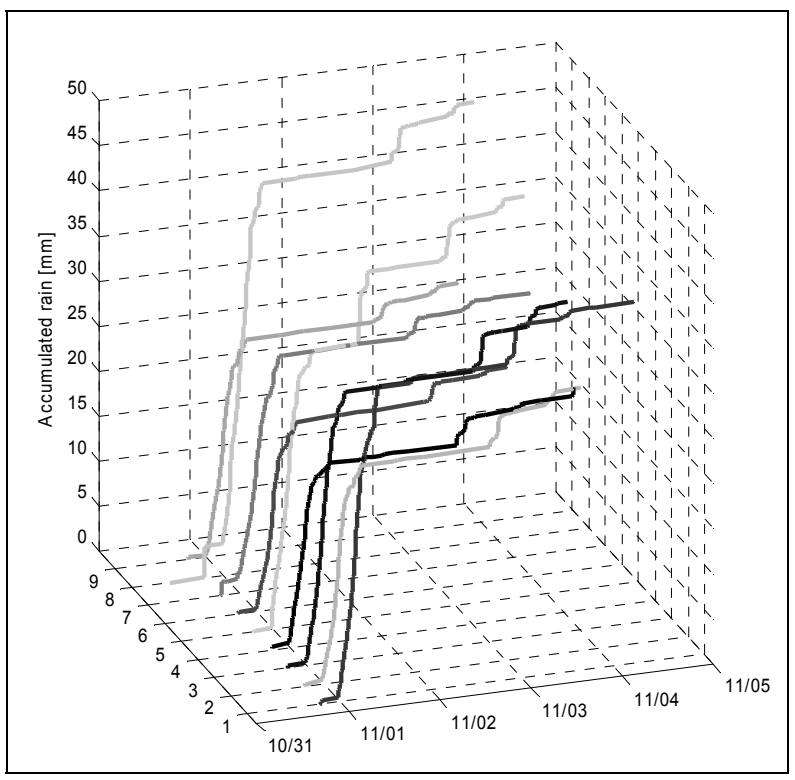

Figure 5.3 Accumulated rainfall in event 17 over time. 


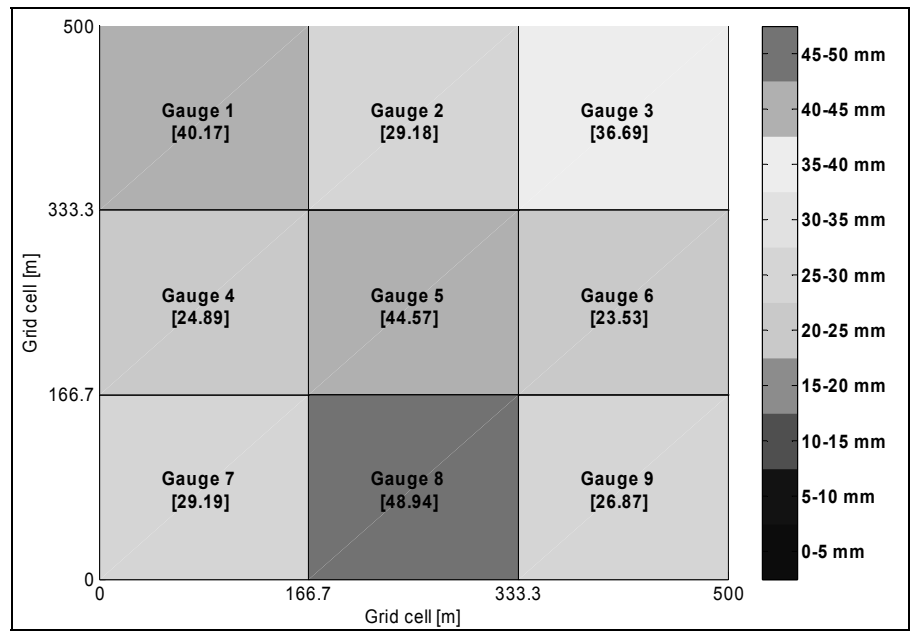

Figure 5.4 Distribution of accumulated rainfall in event 17 . The figures in brackets are the accumulated rainfall for the gauge in $\mathrm{mm}$.

\subsection{LAWR Calibration}

The LAWR radar was calibrated using the DHI-approach. This calibration uses the count values without any transformation. The calibration is assuming the counts and the rain intensity $[\mathrm{mm} / 5$ minutes] are proportional.

The DHI calibration is a direct calibration, where the output in counts from the Søsterhøj Radar and a rain rate measured by high resolution rain gauges are fitted to a first order expression:

$$
R=\text { DHI factor } \cdot \text { counts }
$$

The DHI factor of the fitted expression is found together with the goodness of fit values, coefficient of determination, $\mathrm{R}^{2}$ and root mean squared error (RMSE).

The result from fitting the average rate with counts from event 17 can be seen in Figure 5.5. The shape of the data indicates that a higher order polynomial would yield a better fit, but after examination of a fit with higher order polynomials, it is concluded that the improvement is insignificant if 
the $\mathrm{R}^{2}$ and RMSE values are used as indicators of the fit. As a result, the first order expression is chosen for further analysis.

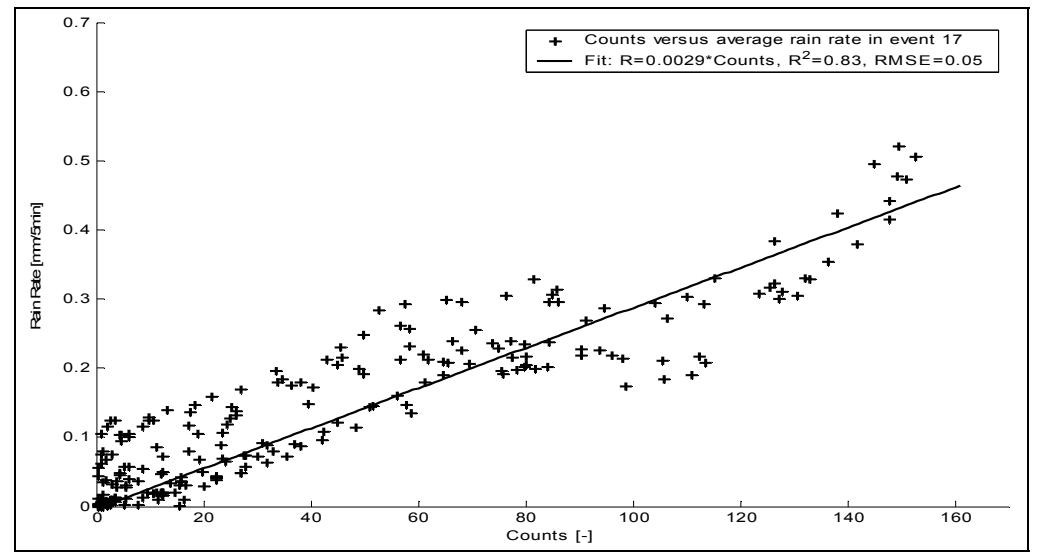

Figure 5.5 Counts and rain rates fitted to a first order expression.

The coefficient of determination $\mathrm{R}^{2}=0.83$ is smaller than the one found in Jensen (2002) of 0.88, but, since that calibration in Jensen (2002) was performed using a single rain gauge, and not nine as here, the values are not directly comparable.

Table 5.2 DHI factors obtained by fitting the rain rates in event 17 from the individual gauges with the counts. The factors are for converting counts into $\mathrm{mm} \mathrm{h}^{-1}$.

\begin{tabular}{lccc}
\hline Gauge No. & DHI-factor & $\mathrm{R}^{2}$ & RMSE \\
\hline 1 & 0.0420 & 0.7240 & 0.9704 \\
2 & 0.0336 & 0.8630 & 0.5548 \\
3 & 0.0396 & 0.8390 & 0.6608 \\
4 & 0.0276 & 0.8218 & 0.5096 \\
5 & 0.0372 & 0.6164 & 1.0474 \\
6 & 0.0276 & 0.8071 & 0.5830 \\
7 & 0.0288 & 0.6395 & 0.7416 \\
8 & 0.0444 & 0.3066 & 0.1996 \\
9 & 0.0312 & 0.8746 & 0.4846 \\
Average rate & 0.0348 & 0.8287 & 0.5915 \\
\hline
\end{tabular}




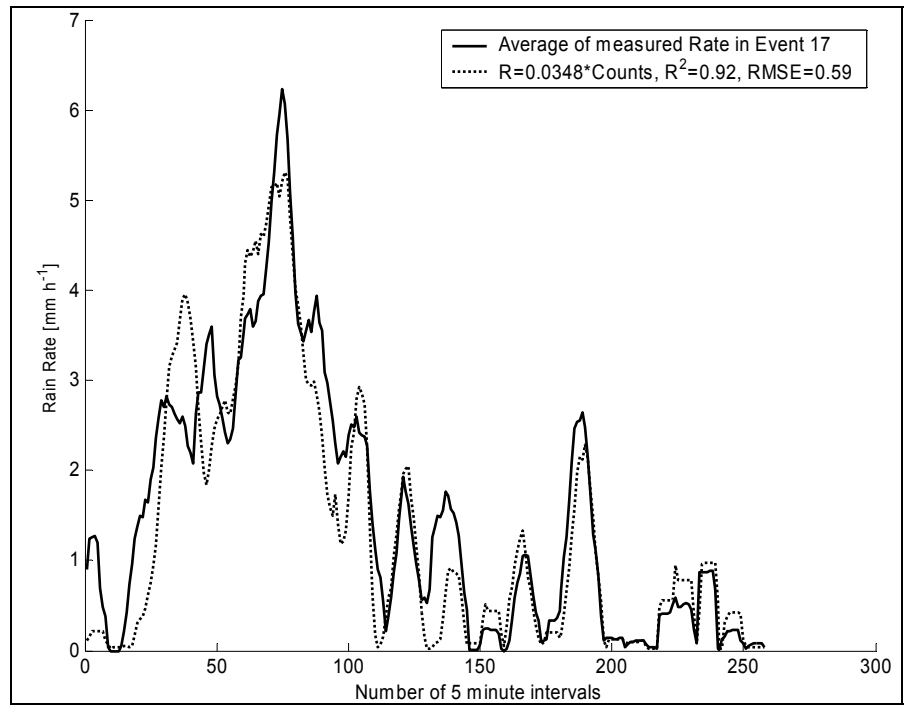

Figure 5.6 The calculated rate on basis of the DHI calibration factor compared with the measured rate for event 17.

The DHI calibration with data from the $250 \times 250 \mathrm{~m}$ grid gives the calibration factors shown in Table 5.2.

Table 5.2 DHI factors for event 17 along with goodness of fit values for LAWR-250.

\begin{tabular}{lccc}
\hline & DHI factor & R2 & RMSE \\
\hline Gauge 1 versus cell no. $(125,163)$ & 0.0432 & 0.7189 & 0.9792 \\
Gauge 3 versus cell no. $(126,164)$ & 0.0396 & 0.8402 & 0.6588 \\
Gauge 7 versus cell no. $(125,164)$ & 0.0294 & 0.7683 & 0.5964 \\
Gauge 9 versus cell no. $(126,164)$ & 0.0324 & 0.8680 & 0.4980 \\
\hline
\end{tabular}

\subsection{Run-off Simulation}

Event 17 has been subdivided into a number of individual sub-events (see Figure 5.7). The major sub-event has been selected for further analyses.

Figures 5.8, 5.9 and 5.10, on the following pages, clearly show that substantial variability exists on a single sub event level. 




Figure 5.7 Event 17 consists of 1 major event and 7 smaller ones.

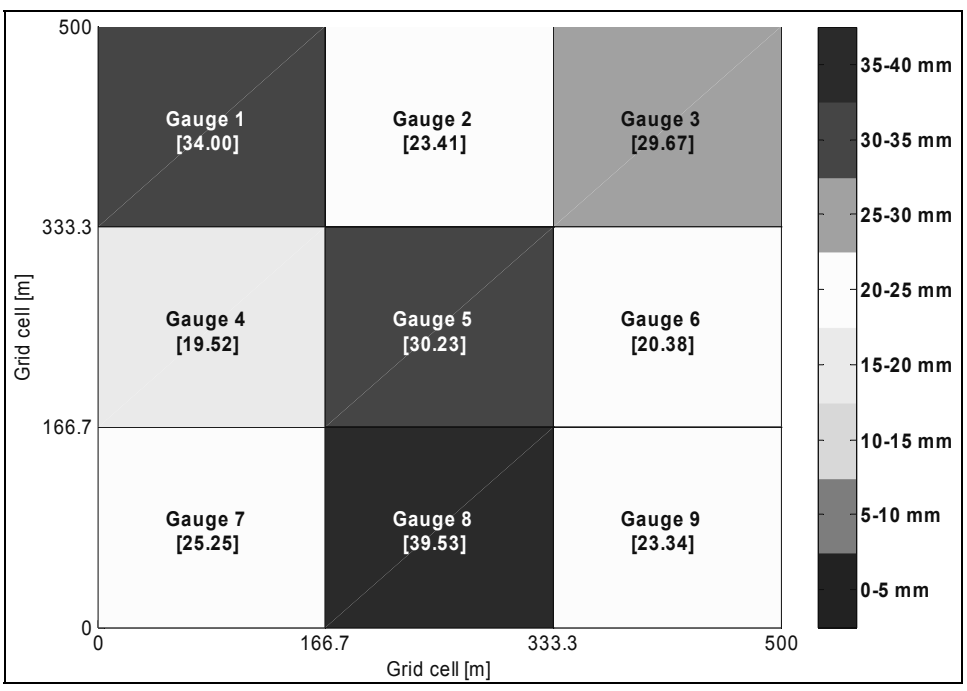

Figure 5.8 Spatial variability for sub event 1 . Covariance is $24.61 \%$. 


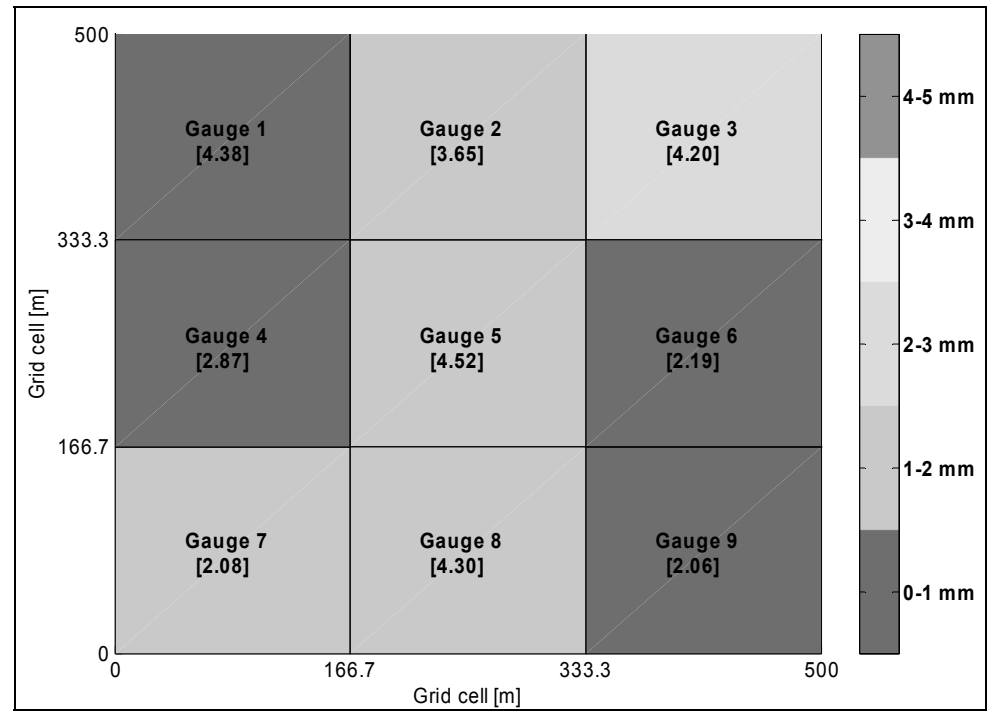

Figure 5.9 Spatial variability for sub event 2. The covariance is $31.52 \%$.

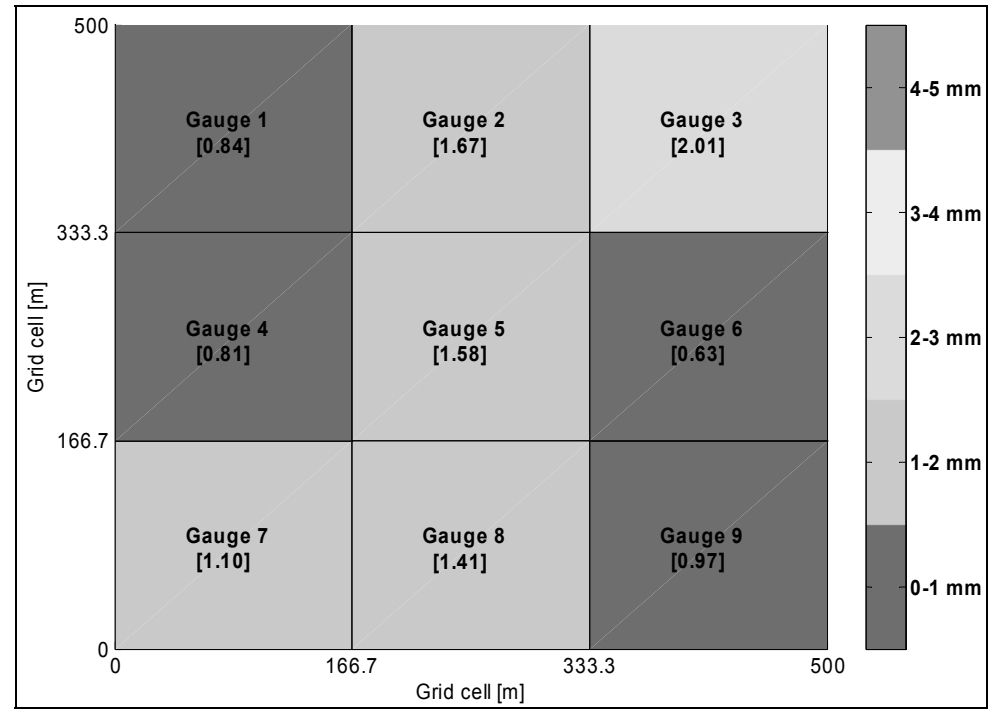

Figure 5.10 Spatial variability for sub event 3 . The covariance is $38.17 \%$. 
There is $102 \%$ difference between the largest and smallest rainfall amount in sub event 1 , which is in the same order as the differences found for events consisting of several sub events. The difference for sub event 2 and 3 are $119 \%$ and $219 \%$ respectively, indicating that the variability is largest when the rainfall amount is small.

\subsection{Variability in Discharge from Catchments}

To examine the variability in relation to run-off from a catchment is the $500 \times 500$ meter area with the rain gauges regarded as a catchment. The discharge from surface run-off from the catchment into a manhole, just outside the catchment is determined on the basis of the different setups in Figure 5.15.

The analysis is carried out with rainfall data from the period covering sub event 1 of event 17 . The Time-Area method is used to determine the discharge and the discharge volume from the catchment on the basis of the rainfall in sub event 1 . The setups are simulated in MOUSE with standard parameters. MOUSE is a software tool developed by DHI Water \& Environment for the simulation of hydrology, hydraulics, water quality and sediment transport in urban drainage and sewer systems

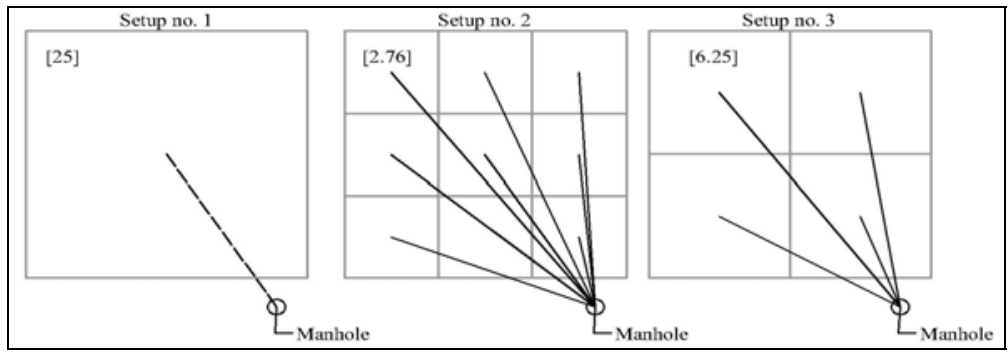

Figure 5.11 The different methods the rainfall is applied to the $500 \mathrm{x}$ $500 \mathrm{~m}$ catchment. Figures in brackets are the catchment area in ha. The dotted line in Setup 1 illustrates the path of the run-off, and is not a pipe.

The 500x500 meter area in setup no. 1 is regarded as one single catchment. The nine rain gauge time series for event 17 and the average time series are applied individually to simulate the difference. Furthermore the time series from LAWR-500 is applied to this setup. 
The 500x500 meter area in setup no. 2 has been divided into nine sub catchments and the inter-related rain gauge time series are applied. The output hydrograph from setup 2 is considered to be the true hydrograph from the catchment, since it contains information from all nine time series. Setup no. 3 is similar to setup no. 2 but is for simulating the discharge on basis of LAWR-250 data. The discharge graphs from the three different setups are compared and the differences in discharge volumes are determined.

\subsection{Results and Discussion}

Figure 5.12 clearly shows how sensitive it is to describe a catchment with only one rain gauge. The variation in the hydrographs is much smaller if the discharge hydrograph are determined on basis of LAWR data as Figure 5.13 shows, which is due to the fact that LAWR is averaging over an area.

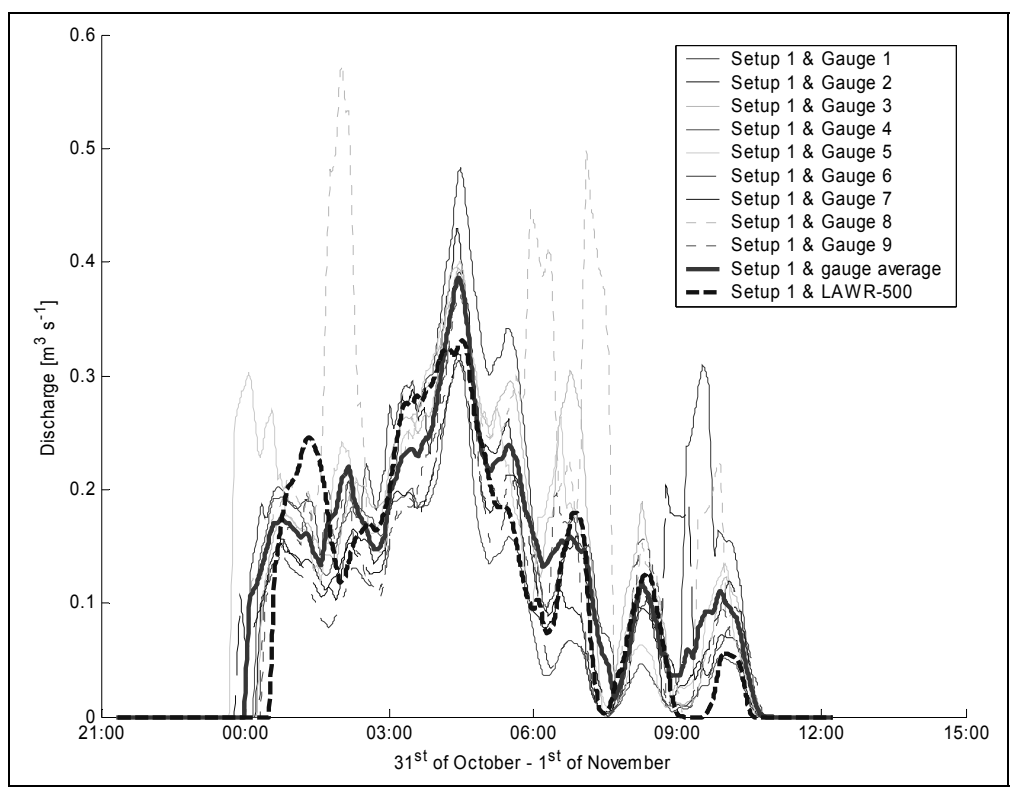

Figure 5.12 Discharge hydrographs from the manhole on the basis of setup 1 and simulation with the time series individually. The thick solid line is on the basis of a gauge average, while the dotted line is on the basis of LAWR-500. 


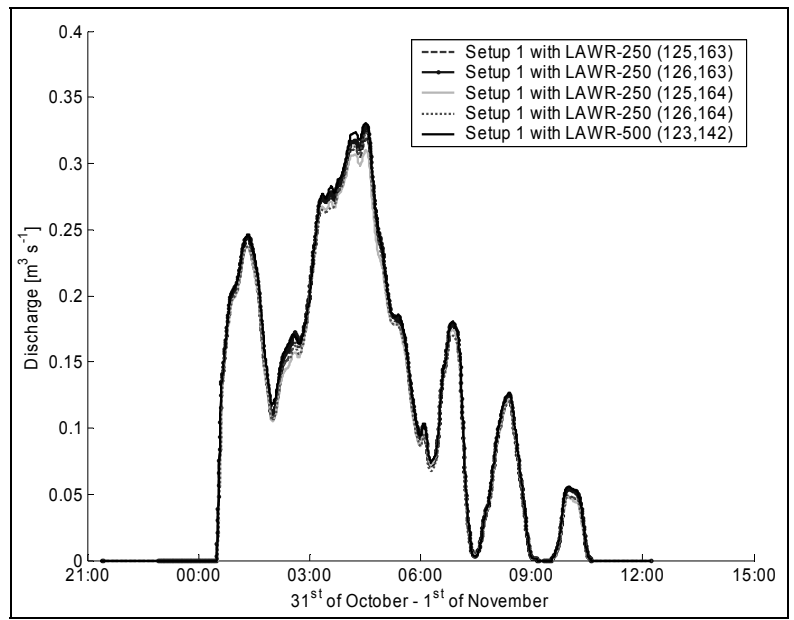

Figure 5.13 Discharge hydrographs from the manhole on the basis of setup 1 and LAWR data.

The different discharge hydrographs from setup 1 and 2 can be seen in Figure 5.14, where the discharge hydrograph based on the average rate are almost identical with the one based on nine sub catchments.

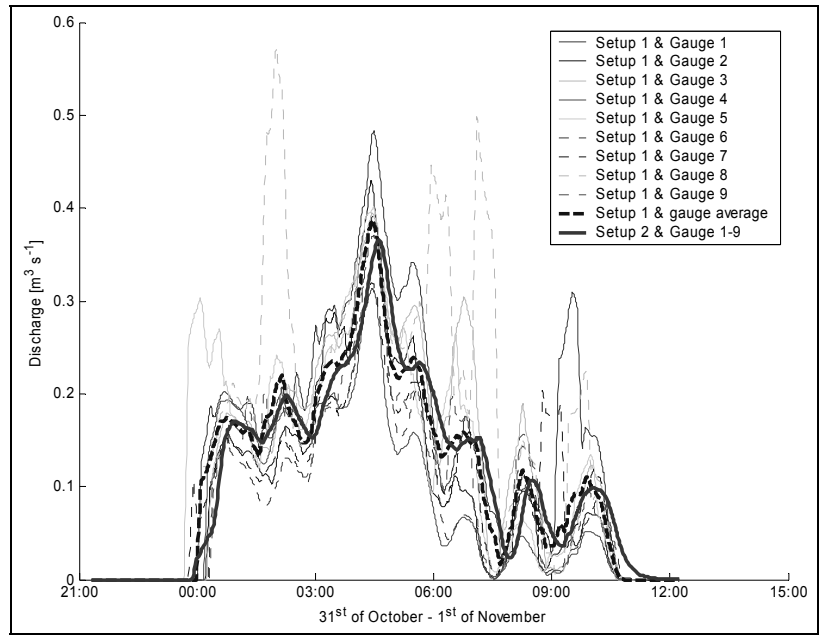

Figure 5.14 Discharge hydrographs from the manhole on the basis of setup 1 and 2 with rain gauge data. 
On the basis of the presented discharge hydrographs it can be concluded that it is very uncertain to use a single gauge for determining the discharge volume from a given catchment. This is verified by Figure 5.15 showing the accumulated outflow profiles. The difference in discharge volumes is very large with a mean of $5,975 \mathrm{~m}^{3}$ and a standard deviation of $1,417 \mathrm{~m}^{3}$.

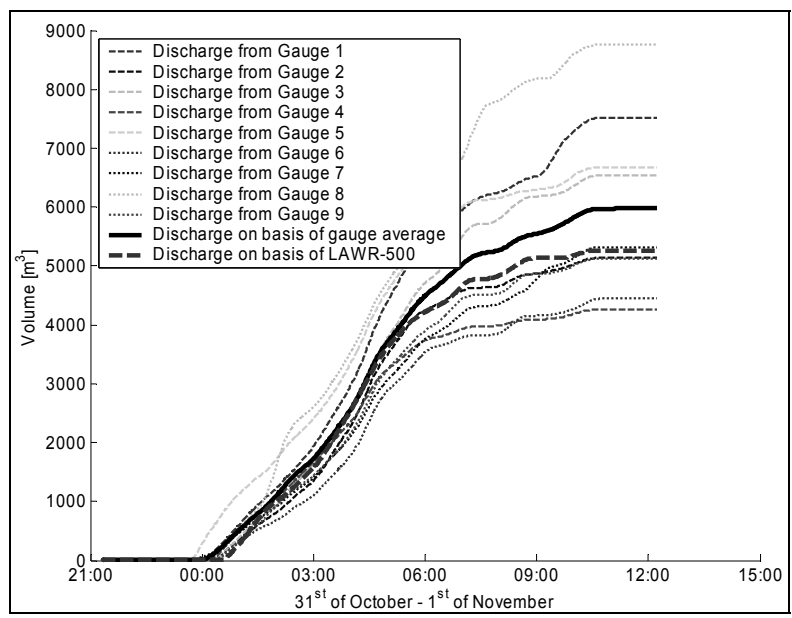

Figure 5.15 Accumulated discharge volumes on basis of setup 1 .

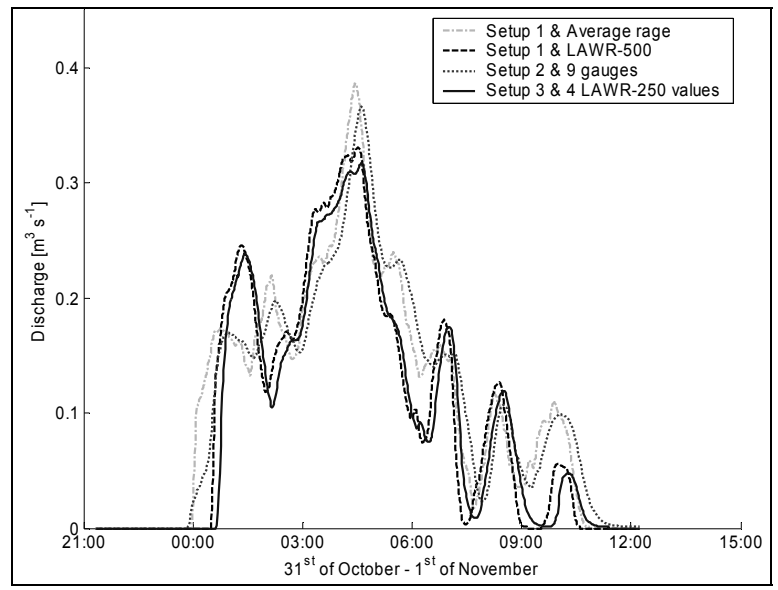

Figure 5.16 Discharge hydrographs from the manhole on the basis of setup 1,2 and 3 . 
From the discharge hydrographs for the three setups it can bee seen that they are very similar to Setup 1 using the average gauge as illustrated in Figure 5.16.

Simulation with radar rainfall in higher resolution has not been tested, but the rainfall series presented by the radar images below suggests that significant improvements can be obtained using such information.

\subsubsection{Radar Pixel Size}

In Figure 5.17 the accumulated rainfall is shown for a different spatial resolution. Due to the integration technique used in the LAWR radar system, which ignores reflectivity under a certain 'noise' threshold level, larger pixels tends to slightly overestimate light precipitation. The variations shown suggest that $100 \times 100 \mathrm{~m}$ pixels (or smaller) should be used when feeding rainfall information into urban run-off models.

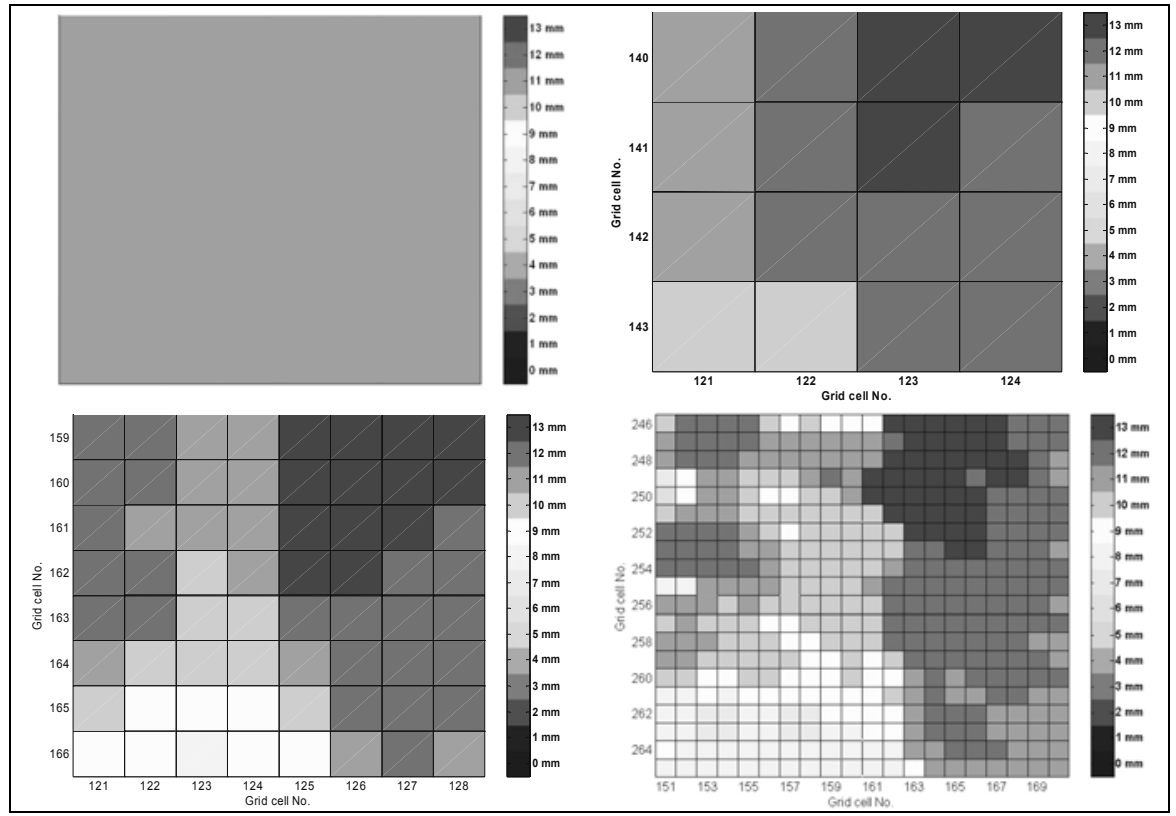

Figure 5.17 An accumulated rainfall at $2 \times 2 \mathrm{~km}, 500 \times 500 \mathrm{~m}, 250 \times$ $250 \mathrm{~m}$ and $100 \times 100 \mathrm{~m}$ pixel size for an event on May $5^{\text {th }} 2004$ with a total duration of 7 hours and 40 minutes. 


\subsubsection{Pixel Size Limitations on Weather Radars}

Many operational radars, use a beam width of one degree. As a result the beam is $100 \mathrm{~m}$ wide at a distance of only $5.7 \mathrm{~km}$ from the radar. Since the power emitted from the radar antenna has a peak in the middle of the beam, the 100 by $100 \mathrm{~m}$ resolution may be used as far as $10 \mathrm{~km}$ away from the radar. As a result of this, only radars placed with a distance less that $10 \mathrm{~km}$ from the urban catchments might be used as a source for rainfall estimates for urban run-off simulation.

As the results suggest, it is difficult to base run-off simulation on a sparse net of rain gauges. Depending on a (random) selection of one of the nine rain gauges, the accumulated run-off volume varies up to $100 \%$. There are two sources of this variation: the variability in rainfall from a given position relative to the cloud and the variability caused by the movement of the cloud. Figure 5.18 shows the percentage of the catchment (pixel) receiving rainfall as a function of time. It can be seen that over a substantial period of time only a fraction of the $500 \times 500 \mathrm{~m}$ pixel is exposed to precipitation. In this study it has not been possible to distinguish between these two sources, but it would be relevant to identify what is more important: accuracy on rainfall volume or accuracy on area receiving rainfall.



Figure 5.18 Precipitation coverage (\%) over the rainfall event. 


\subsection{Conclusion}

Urban runoff is characterized with fast response due to large impermeable areas. Each small part of the catchments responds immediately to variations in the rainfall and modeling of such catchments is very dependent on accurate precipitation information. Unfortunately most rainfall-run-off simulations are based on very few rain gauges. Typically only one or two rain gauges are providing rainfall input to the models. The large variation in rainfall over very short distances suggests that rain gauges alone cannot provide a realistic image of the precipitation over catchments. In order to obtain this information, rain-gauge measurements should be combined with weather radar measurements in a resolution not exceeding $100 \times 100 \mathrm{~m}$.

\section{References}

Atlas, D., C.W. Ulbrich, F.D. Marks Jr., E. Amitai and C.R. Williams (1999), Systematic variation of drop size and radar-rainfall relations, Journal of Geophysical Research, Vol. 104, No. D6, Pages 6155-6169.

Battan, L. J. (1973), Radar Observations of the Atmosphere, The University of Chicago Press, Chicago and London.

Canfield, H. E., Goodrich, D. C., Studies of Scale and Processes in Hydrologic Modeling on the Lucky Hills Watershed. Agricultural Research Service, Southwest Watershed Research Center, Tucson, AZ 85719

DHI (2003), MOUSE reference manual (runoff), DHI Water \& Environment, Copenhagen, Denmark.

DMI (2004b), Spildevandskomiteens regnmåler system, (online) http://www.dmi.dk/dmi/spildevandskomiteens_regnmaalersystem.

Hjortdal, P., J. Sørensen (2003), Brug af vejrradar til generering af lokale regnhoendelser, danskVand, nr. 8, Okt. 2003.

IDA Spildevandskomitéen (1999), Regional variation af ekstremregn iDanmark, Skrift nr. 26, Spildevandskomitéen.

Jensen, N. E. (2002), X-Band local area weather radar-preliminary calibration results, Water Science and Technology, Vol 45 No 2 pp 135-138.

Larsen, T. (1998), Introduktion til Analyse af tidsserier inden for miljøteknik og vandbygning, Instituttet for Vand, Jord og Miljøteknik, Aalborg Universitet.

Lee, G. W. (2003) Errors in rain measurements by radar: effect of variability of drop size distributions, Dept of Atmos. \& Oceanic Sciences, McGill Univ, Montreal, Canada.

Overgaard, S., N. E. Jensen (2001), Performance of Small X-band Weather Radarpreliminary evaluation of the FUENEN LAWR WEATHER RADAR, 2002 Western Pacific Geophysics Meeting.

Rinehart, R. E. (1997), Radar for Meteorologists, Third Edition, Rinehart Publishing, Colombia, USA. 